\title{
Desempenho de vacas em lactação alimentadas com dietas contendo torta de macaúba
}

\author{
[Performance of dairy cows fed diets containing macauba meal] \\ R.A. Azevedo ${ }^{1}$, A.C.R. Santos $^{1}$, C.S. Ribeiro Júnior ${ }^{1}$, F.P.C. Santos ${ }^{1}$, L. Araújo ${ }^{1}$, \\ F.L. Bicalho ${ }^{1}$, L.M. Fonseca ${ }^{2}$, L.C. Geraseev ${ }^{1 *}$ \\ ${ }^{1}$ Instituto de Ciências Agrárias - Universidade Federal de Minas Gerais - ICA/UFMG - Montes Claros, MG \\ ${ }^{2}$ Escola de Veterinária - Universidade Federal de Minas Gerais - EV/UFMG - Belo Horizonte, MG
}

\section{RESUMO}

Avaliaram-se o consumo de nutrientes e a produção e composição do leite de vacas da raça Holandesa alimentadas com dietas contendo diferentes quantidades de inclusão de torta de macaúba. Oito animais foram distribuídos em dois quadrados latinos $4 \times 4$, sendo quatro tratamentos, 0, 100, 200 e $300 \mathrm{~g} \mathrm{~kg}^{-1} \mathrm{de}$ TM na matéria seca da dieta, e quatro períodos experimentais de 21 dias, 14 de adaptação e sete de avaliações. A adição de quantidades crescentes de torta de macaúba à dieta alterou o consumo de matéria seca, matéria orgânica, proteína bruta, extrato etéreo, fibra em detergente neutro, carboidratos não fibrosos, produção e os teores de lactose, extrato seco desengordurado e sólidos totais do leite, bem como a eficiência alimentar e a digestibilidade da matéria seca. Por outro lado, não foi verificada diferença nos teores de gordura do leite. A adição da TM em até $300 \mathrm{~g} \mathrm{~kg}^{-1}$ da dieta comprometeu o consumo e o desempenho produtivo dos animais.

Palavras-chave: bovinos, Acrocomia aculeata sp., confinamento, leite, produção

\begin{abstract}
We evaluated nutrient intake, production and composition of milk from Holstein cows fed feedlot diets with different inclusion levels of macauba meal. Eight animals were divided into two $4 x 4$ latin square designs, four treatments, 0, 100, 200 and 300 $\mathrm{g} \mathrm{kg}^{-1}$ macauba meal in the dry matter diet, and four experimental periods of 21 days, 14 adaptation and seven evaluation The addition of increasing levels of macauba meal diet alter the intake of dry matter, organic matter, crude protein, ether extract, neutral detergent fiber, non-fiber carbohydrates, production and concentration of lactose, nonfat dry and total solids in milk, as well as the feed efficiency and digestibility of dry matter. Moreover, there was no difference in the levels of milk fat. The addition of macaúba meal up to $300 \mathrm{~g} \mathrm{~kg}^{-1}$ diet compromised the consumption and production performance of animals.
\end{abstract}

Keywords: cattle, Acrocomia aculeata sp., feedlot, milk, production

\section{INTRODUÇÃO}

A elevação e a oscilação nos preços dos componentes concentrados da dieta demonstram a necessidade de se avaliar a substituição destes por alimentos alternativos de menores custos e que, apresentando adequada qualidade, sejam capazes de manter a produção dos rebanhos (Pimentel et al., 2012).

Recebido em 23 de fevereiro de 2013

Aceito em 20 de agosto de 2013

*Autor para correspondência (corresponding author)

E-mail: lgeraseev@gmail.com
Uma alternativa é a substituição dos alimentos convencionais por coprodutos na formulação de dietas para animais em produção, como resíduos da agroindústria do biodiesel, os quais podem consistir em fontes interessantes de proteína, energia e fibra. Coprodutos são alimentos alternativos para a alimentação de ruminantes, os quais apresentam capacidade de utilizar resíduos vegetais para suprir seus requisitos nutricionais, além de substituírem, de forma parcial ou total, 
os alimentos concentrados padrões das dietas, como o milho e o farelo de soja (Pires et al., 2005; Silva et al., 2005).

A torta de macaúba (TM), resíduo proveniente da extração do óleo do fruto dessa palmeira, é um coproduto comumente encontrado em regiões do semiárido brasileiro. Análises químicas realizadas nas tortas residuais do fruto da macaúba demonstram que esse coproduto poderia ser aproveitado na alimentação de ruminantes, dado seu alto teor de energia (Rufino et al., 2011; Azevedo et al., 2012) e por ser uma alternativa técnica e economicamente viável para a substituição do milho na dieta de vacas leiteiras (Azevedo et al., 2013).

Existem poucos trabalhos na literatura científica consultada a respeito da utilização desse coproduto na alimentação de vacas em lactação, sendo necessárias pesquisas para avaliar os efeitos do seu uso sobre o desempenho, produção e composição do leite. Nesse contexto, objetivou-se avaliar o consumo de nutrientes, o desempenho produtivo, a constituição do leite e a digestibilidade das dietas fornecidas para vacas Holandesas alimentadas com diferentes quantidades de inclusão de TM.

\section{MATERIAL E MÉTODOS}

O experimento foi conduzido no Setor de Bovinocultura do Instituto de Ciências Agrárias da Universidade Federal de Minas Gerais (ICA/UFMG), Montes Claros, Minas Gerais, Brasil, sendo avaliado e aprovado pelo Comitê de Ética em Experimentação Animal da UFMG, sob o protocolo de número 87/2008.

Foram utilizadas oito vacas Holandesas com $480 \pm 26 \mathrm{~kg}$ de peso corporal, com média de produção de $21,4 \pm 3,8 \mathrm{~kg}$ dia $^{-1}$, na segunda lactação, idade média de 4,1 $\pm 0,2$ anos e com 45 dias de lactação. Os animais foram alojados em baias cobertas e individuais, com $6 \mathrm{~m}^{2}$, piso de terra batida, bebedouros automáticos, comedouros e saleiros individuais, sendo distribuídos em dois quadrados latinos $4 \times 4$, balanceados para efeito residual, sendo quatro tratamentos com diferentes quantidades de inclusão da TM $\left(0,100,200\right.$ e $300 \mathrm{~g} \mathrm{~kg}^{-1}$ de MS) na dieta total e quatro períodos experimentais, de 21 dias cada, sendo os primeiros 14 dias de adaptação dos animais à dieta e os últimos sete dias para realização das coletas de dados.

Os animais receberam dietas completas com $500 \mathrm{~g} \mathrm{~kg}^{-1}$ de volumoso (silagem de milho) e $500 \mathrm{~g} \mathrm{~kg}^{-1}$ de concentrado (caroço de algodão, farelo de milho, farelo de soja, torta de macaúba, ureia pecuária + sulfato de amônia, calcário calcítico, fosfato bicálcico, suplemento mineral e vitamínico). A torta de macaúba utilizada foi doada pela Cooperativa de Pequenos Produtores Rurais de Riacho D'Antas e Adjacências, localizada em Montes Claros, Minas Gerais, Brasil.

As dietas experimentais foram formuladas de acordo com as recomendações do NRC (National..., 2001) para atender às exigências de mantença e de produção de vacas com média de $500 \mathrm{~kg}$ de peso corporal, produzindo $25 \mathrm{~kg}$ de leite $\mathrm{dia}^{-1}$, com teor de $34 \mathrm{~g} \mathrm{~kg}^{-1}$ de gordura e $30 \mathrm{~g} \mathrm{~kg}^{-1}$ de proteína (Tab. 1).

A alimentação foi fornecida duas vezes ao dia, às $7 \mathrm{~h}$ e às $17 \mathrm{~h}$, sendo ajustada de forma a manter sobras de $200 \mathrm{~g} \mathrm{~kg}^{-1}$ do oferecido. As sobras foram retiradas e pesadas diariamente, para determinação do consumo diário. Os consumos dos nutrientes foram expressos em gramas por dia, gramas por quilo de peso corporal ( $\mathrm{g}$ por $\mathrm{kg}$ $\mathrm{PC}$ ) e por unidade de peso metabólico ( $\mathrm{g}$ por $\mathrm{PV}^{-}$ 0,75 ).

Amostras dos alimentos fornecidos e das respectivas sobras foram coletadas diariamente, identificadas e acondicionadas em freezer para posteriores análises laboratoriais. Todas as amostras foram pré-secadas em estufa ventilada a $55^{\circ} \mathrm{C}$ e, posteriormente, moídas em moinho com peneira de $1 \mathrm{~mm}$ e acondicionadas em frascos identificados.

Amostras das dietas e sobras foram analisadas quanto ao conteúdo em matéria seca (MS), matéria mineral (MM), proteína bruta $(\mathrm{PB})$, extrato etéreo (EE) e fibra em detergente neutro (FDN) (Silva e Queiroz, 2002). Os teores de carboidratos não fibrosos (CNF) foram calculados pela equação: $\mathrm{CNF}=100-$ [(PB+EE+MM+FDN] (Weiss, 1999). Os carboidratos totais (CT) foram estimados por meio da equação: $\mathrm{CT}=100-(\mathrm{PB} \%+\mathrm{EE} \%+$ MM\%), e os carboidratos fibrosos (CF), pela equação: CF = CT - CNF (Sniffen et al. 1992). 
Tabela 1. Composição bromatológica das dietas experimentais e da torta de macaúba

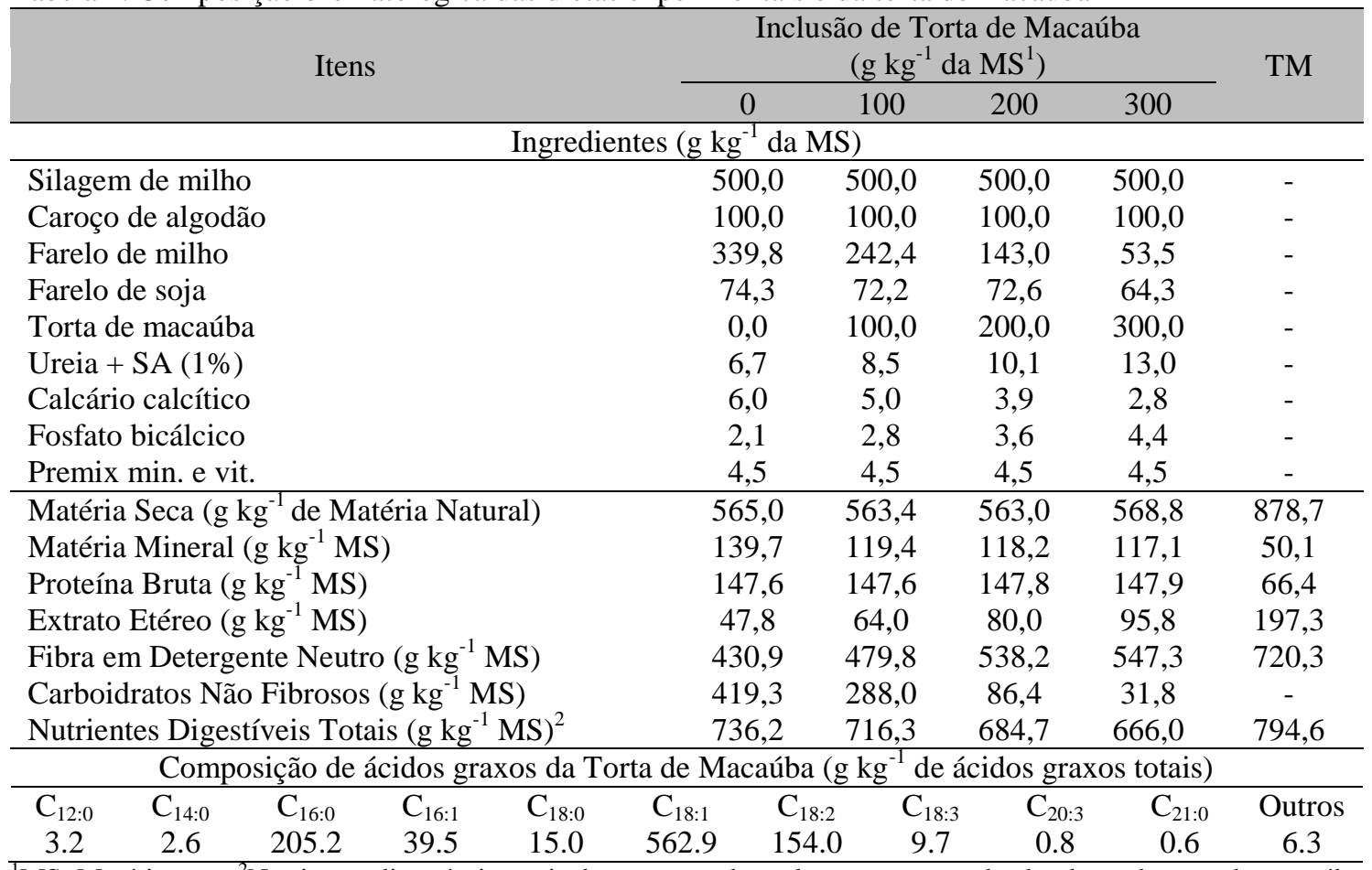

${ }^{\mathrm{T}} \mathrm{MS}$ : Matéria seca; ${ }^{2}$ Nutrientes digestíveis totais do concentrado, volumoso, caroço de algodão e da torta de macaúba calculados, respectivamente, segundo fórmulas propostas por Weiss $(1999)$ : NDT $=40,3227+(0,5398 \mathrm{~PB})+$ $(0,4448 \mathrm{ENN})+(1,4218 \mathrm{EE})-(0,7007 \mathrm{FB}) ; \mathrm{NDT}=-21,9391+(1,0538 \mathrm{~PB})+(0,9738 \mathrm{ENN})+(0,4590 \mathrm{FB})+$ $(3,0016 \mathrm{EE}) ; \mathrm{NDT}=40,2625+(0,1969 \mathrm{~PB})+(0,4228 \mathrm{ENN})+(1,1903 \mathrm{EE})-(0,1379 \mathrm{FB}) ; \mathrm{NDT}=40,2625+0,1969 \mathrm{~PB}+$ $(0,4028 \mathrm{ENN})+(1,903 \mathrm{EE})-(0,1379 \mathrm{FB})$

A composição de ácidos graxos da TM foi determinada de acordo com Machmu Èller e Kreuzer (1999). Realizou-se extração com clorofórmio-metanol (2:1, v/v) e metilação dos lipídeos, sendo posteriormente determinados e quantificados os ácidos graxos em cromatógrafo de gás HP 5890A (Hewlett-Packard ${ }^{\circledR}$, Avondale, PA, EUA), equipado com um Supelcowax 10coluna (Coluna capilar de sílica fundida, $30 \mathrm{~m} \mathrm{x}$ $0,32 \mathrm{~mm})$.

Amostras dos concentrados fornecidos foram secos em estufa com circulação forçada e, posteriormente, moídas em moinho com peneiras de $1 \mathrm{~mm}$ para o estudo in vitro, realizado no Laboratório de Nutrição Animal da Escola de Veterinária da UFMG, Belo Horizonte, Minas Gerais, Brasil, pela incubação de $0,5 \mathrm{~g}$ de amostras no fermentador artificial (Daisy II Fermenter $^{\circledR}$ ), segundo metodologia descrita por Tilley e Terry (1963), adaptada por Holden (1999).
As vacas foram ordenhadas duas vezes ao dia, às $6 \mathrm{~h}$ e às $16 \mathrm{~h}$, durante todo o período experimental. Nos três últimos dias, de cada período experimental, a produção foi mensurada pela pesagem do leite, com o auxílio de balança digital. Amostras de $80 \mathrm{~mL}$ de leite cru, proveniente de cada animal por período, foram conservadas com bronopol, sendo analisadas quanto aos teores de gordura, proteína, lactose e extrato seco total no equipamento eletrônico Bentley $2000^{\circledR}$ acoplado com o Somacount $300^{\circledR}$ (Bentley Instruments Inc. 4004, Peavey Road Chaska, MN 55318 U), no Laboratório de Análise de Leite da Escola de Veterinária da UFMG, Belo Horizonte, Minas Gerais, Brasil. A eficiência da conversão alimentar da produção de leite foi estimada pela relação entre a produção diária de leite corrigida e o consumo de matéria seca $\left(\mathrm{g} \mathrm{dia}^{-1}\right)$.

Os resultados foram submetidos à análise de variância e de regressão, levando-se em conta as homogeneidades das variâncias. Para todas as 
variáveis, foi adotado significância de $5 \%$ de probabilidade (Statistical..., 2002).

\section{RESULTADOS E DISCUSSÃO}

Houve efeito da inclusão da TM $(\mathrm{P} \leq 0,05)$ sobre o consumo de matéria seca e de matéria orgânica em $\mathrm{g} \mathrm{dia}{ }^{-1}$, sendo observado comportamento quadrático. Os máximos consumos estimados para matéria seca e matéria orgânica corresponderam, respectivamente, a inclusão de $5,43 \mathrm{~g} \mathrm{~kg}^{-1}$ e $3,03 \mathrm{~g} \mathrm{~kg}^{-1}$ de TM. Ocorreu redução linear $(\mathrm{P} \leq 0,05)$ de ambos os consumos, quando expressos em $\mathrm{g} \mathrm{kg}^{-1}$ de peso corporal e metabólico, de acordo com a inclusão da torta nas dietas (Tab. 2).

Tabela 2. Médias para o consumo de matéria seca (CMS), matéria orgânica (CMO), proteína bruta (CPB), extrato etéreo (CEE), fibra em detergente neutro (CFDN) e carboidratos não fibrosos (CCNF) em função das quantidades de torta de macaúba nas dietas de vacas Holandesas em lactação

\begin{tabular}{|c|c|c|c|c|c|c|c|}
\hline \multirow{2}{*}{ Variáveis } & \multicolumn{4}{|c|}{ Inclusão de TM ( $\mathrm{g} \mathrm{kg}^{-1}$ da matéria seca) } & \multirow{2}{*}{ E.P.M $M^{1}$} & \multicolumn{2}{|c|}{ Efeito } \\
\hline & 0 & 100 & 200 & 300 & & $\mathrm{~L}$ & Q \\
\hline $\operatorname{CMS}\left(\mathrm{g} \mathrm{dia}^{-1}\right)^{2}$ & 18360,0 & 18410,0 & 16690,0 & 15190,0 & 0,20 & 0,01 & 0,01 \\
\hline CMS $\left(\mathrm{g} \mathrm{kg}^{-1} \mathrm{PC}\right)^{3}$ & 39,70 & 38,10 & 35,60 & 33,0 & 0,04 & 0,01 & 0,30 \\
\hline CMS $\left(\mathrm{g} \mathrm{kg}^{-0,75}\right)^{4}$ & 184,50 & 178,70 & 165,8 & 153,0 & 0,19 & 0,01 & 0,16 \\
\hline $\mathrm{CMO}\left(\mathrm{g} \mathrm{dia}^{-1}\right)^{5}$ & 16770,0 & 16820,0 & 15230,0 & 13880,0 & 0,01 & 0,01 & 0,01 \\
\hline $\mathrm{CMO}\left(\mathrm{g} \mathrm{kg}^{-1} \mathrm{PC}\right)^{6}$ & 35,9 & 34,8 & 32,5 & 30,2 & 0,19 & 0,01 & 0,20 \\
\hline $\mathrm{CMO}\left(\mathrm{g} \mathrm{kg}^{-0,75}\right)^{7}$ & 166,9 & 163,3 & 151,30 & 139,8 & 0,04 & 0,01 & 0,10 \\
\hline CPB $\left(\mathrm{g} \mathrm{dia}^{-1}\right)^{8}$ & 2690,0 & 2600,0 & 2290,00 & 1960,0 & 0,18 & 0,01 & 0,02 \\
\hline $\mathrm{CPB}\left(\mathrm{g} \mathrm{kg}^{-0,75}\right)^{9}$ & 26,80 & 25,20 & 22,80 & 19,80 & 0,01 & 0,01 & 0,12 \\
\hline $\operatorname{CEE}\left(\mathrm{g} \mathrm{dia}^{-1}\right)^{10}$ & 1100,00 & 1150,00 & 1140,00 & 1040,00 & 0,02 & 0,85 & 0,03 \\
\hline CFDN $\left(\mathrm{g} \mathrm{dia}^{-1}\right)^{11}$ & 7810,00 & 8640,00 & 8860,00 & 8460,00 & 0,10 & 0,01 & 0,01 \\
\hline CFDN $\left(\mathrm{g} \mathrm{kg}^{-1} \mathrm{PC}\right)^{12}$ & 16,60 & 17,90 & 18,90 & 18,40 & 0,02 & 0,01 & 0,01 \\
\hline $\operatorname{CCNF}\left(\mathrm{g} \mathrm{dia}^{-1}\right)^{13}$ & 5150,00 & 4080,00 & 2090,00 & 1573,00 & 0,10 & 0,01 & 0,01 \\
\hline
\end{tabular}

${ }^{1}$ Erro padrão da média; ${ }^{2} \mathrm{y}=-0,0388 \mathrm{x}^{2}+0,4219 \mathrm{x}+18461\left(\mathrm{R}^{2}=0,50\right) ;{ }^{3} \mathrm{y}=-0,0225 \mathrm{x}+40,039\left(\mathrm{R}^{2}=0,55\right) ;{ }^{4} \mathrm{y}=-$ $0,1077 \mathrm{x}+186,72\left(\mathrm{R}^{2}=0,52\right) ;{ }^{5} \mathrm{y}=-0,0349 \mathrm{x}^{2}+0,2118 \mathrm{x}+16865\left(\mathrm{R}^{2}=0,49\right) ;{ }^{6} \mathrm{y}=-0,0195 \mathrm{x}+36,324\left(\mathrm{R}^{2}=0,53\right) ;{ }^{7} \mathrm{y}$ $=-0,0936 \mathrm{x}+169,4\left(\mathrm{R}^{2}=0,50\right) ;{ }^{8} \mathrm{y}=-0,0061 \mathrm{x}^{2}-0,6612 \mathrm{x}+2703,3\left(\mathrm{R}^{2}=0,51\right) ;{ }^{9} \mathrm{y}=-0,0234 \mathrm{x}+27,214\left(\mathrm{R}^{2}=0,53\right)$; ${ }^{10} \mathrm{y}=-0,0039 \mathrm{x}^{2}+0,967 \mathrm{x}+1105,5\left(\mathrm{R}^{2}=0,25\right) ;{ }^{11} \mathrm{y}=-0,0308 \mathrm{x}^{2}+11,398 \mathrm{x}+7813,9\left(\mathrm{R}^{2}=0,41\right) ;{ }^{12} \mathrm{y}=-0,00005 \mathrm{x}^{2}+$ $0,02015 \mathrm{x}+16,54095\left(\mathrm{R}^{2}=0,48\right) ;{ }^{13} \mathrm{y}=-12,759 \mathrm{x}+5142,5\left(\mathrm{R}^{2}=0,90\right)$.

A redução no consumo de MS verificada pode ser atribuída, em parte, ao aumento dos teores de extrato etéreo e de fibra em detergente neutro nas dietas com a inclusão do coproduto (Tab. 1). O NRC (National..., 2001) estabelece o teor limite de $80 \mathrm{~g} \mathrm{~kg}^{-1}$ de extrato etéreo dietético nas dietas de vacas em lactação, pois valores superiores a este podem reduzir o consumo de MS. Pode ser observado que as dietas com 200 e $300 \mathrm{~g} \mathrm{~kg}^{-1}$ de inclusão de torta apresentaram valores de extrato etéreo similar ou superior ao limite recomendado (Tab. 1).

Pereira et al. (2011) não encontraram efeito significativo sobre o consumo de MS ao avaliarem diferentes quantidades de inclusão de torta de girassol sobre o consumo de MS de vacas em lactação. Pimentel et al. (2012) verificaram que o consumo de MS não foi alterado em função da inclusão de castanha de caju na dieta de vacas em lactação. Segundo ambos os autores, esses resultados são aceitáveis, uma vez que os teores de EE das rações ficaram abaixo de $80 \mathrm{~g} \mathrm{~kg}^{-1}$.

De acordo com Vargas et al. (2002), o efeito depressor dos lipídeos sobre o consumo de MS pode relacionar-se à inibição do crescimento microbiano e, por consequência, reduzir a fermentação da fibra, reduzindo a taxa de passagem da digesta pelo trato gastrointestinal, proporcionando limitação do consumo de MS.

No presente trabalho, o teor de FDN nas dietas aumentou em função da inclusão do coproduto (Tab. 1), o que também pode ter proporcionado 
redução do consumo de MS. Segundo Forbes (1996), diversos fatores podem atuar na inibição do consumo de MS, sendo que, entre os fatores inerentes ao alimento, destaca-se o teor de FDN da dieta, em função de sua lenta degradação e pela sua baixa taxa de passagem pelo rúmen (Allen, 2000).

Durante o experimento observou-se que os animais apresentaram aceitabilidade reduzida nas dietas com altas inclusões da TM, o que também pode ter contribuído para a redução do consumo de MS. Azevedo et al. (2012) não observaram redução de aceitabilidade de cordeiros em terminação alimentados com a TM e verificaram que a inclusão de até $300 \mathrm{~g} \mathrm{~kg}^{-1}$ do coproduto na dieta não alterou o consumo de MS e o desempenho produtivo dos animais.

Foi observada redução linear $(\mathrm{P} \leq 0,05)$ da digestibilidade in situ da MS dos concentrados de acordo com a inclusão da TM, sendo verificada a seguinte equação: $\mathrm{y}=-0,135 \mathrm{x}+$ $81,103\left(\mathrm{R}^{2}=0,95\right)$. O efeito depressor do aumento dos teores de EE com a inclusão do coproduto (Tab. 1) pode ter proporcionado recobrimento da fibra, dificultando a colonização da microbiota local e reduzindo a degradação ruminal, especialmente da fração fibrosa. A redução de digestibilidade observada pode estar correlacionada com os dados de consumo de MS observados (Tab. 2).

$\mathrm{O}$ consumo de proteína bruta em $\mathrm{g} \mathrm{kg}^{-1}$ por dia foi influenciado pela inclusão de TM $(\mathrm{P} \leq 0,05)$, apresentando comportamento quadrático, com máximo consumo estimado em $54,19 \mathrm{~g} \mathrm{~kg}^{-1}$ de coproduto nas dietas. No entanto, houve redução linear $(\mathrm{P} \leq 0,05)$ para o consumo de $\mathrm{PB}$ expresso $\mathrm{g} \mathrm{kg}^{-1}$ de peso metabólico, reflexo do comportamento do consumo de MS (Tab. 2).

Observou-se comportamento quadrático $(\mathrm{P} \leq 0,05)$ do consumo de EE em função da quantidade de TM nas dietas (Tab. 2), sendo verificado ponto de consumo máximo desse nutriente com $123,97 \mathrm{~g} \mathrm{~kg}^{-1}$ de inclusão do coproduto.

Os consumos diários de fibra em detergente neutro também foram influenciados pela inclusão da TM, apresentando comportamento quadrático $(\mathrm{P} \leq 0,05)$ e ponto máximo estimado a $185 \mathrm{~g} \mathrm{~kg}^{-1}$ de inclusão de coproduto nas dietas.

Segundo Van Soest (1994), o consumo de MS está diretamente relacionado ao conteúdo de FDN das dietas, pois a fermentação e a passagem dessa fração pelo retículo-rúmen são mais lentas que as de outros constituintes dietéticos, apresentando grande efeito no enchimento e no tempo de permanência.

$\mathrm{O}$ resultado de consumo de FDN sugere que a ingestão de MS pode ter sido limitada, em parte, pelo enchimento do compartimento ruminal; pois, segundo Mertens (1987), quando o consumo for limitado por entraves físicos, o consumo de FDN deverá ser mantido próximo ao valor de $12 \mathrm{~g} \mathrm{~kg}^{-1}$ do peso corporal. Baseando-se nessas argumentações, realmente pode ter ocorrido efeito de enchimento ruminal sobre o consumo de MS (Tab. 3), uma vez que as quantidades de $0,100,200$ e $300 \mathrm{~g} \mathrm{~kg}^{-1}$ de inclusão de torta proporcionaram, respectivamente, consumos de FDN de 16,6; 17,$9 ; 18,9$; e $18,4 \mathrm{~g} \mathrm{~kg}^{-1}$ do peso corporal.

$\mathrm{O}$ consumo de carboidratos não fibrosos em $\mathrm{g}$ $\mathrm{dia}^{-1}$ foi influenciado $(\mathrm{P} \leq 0,05)$ pela inclusão do coproduto, sendo verificado efeito quadrático. Entretanto, a equação gerada para essa variável estimou o ponto mínimo fora dos valores de inclusão da TM trabalhados, considerando-se, assim, efeito linear para o consumo de CNF.

O resultado de redução linear para o consumo de CNF pode justificar-se pela redução da concentração de CNF nas dietas com a inclusão do coproduto (Tab.1), pois, com a inclusão da torta, reduziu-se a quantidade de milho nas dietas, ingrediente que apresentou maior teor de CNF em sua composição da dieta.

A produção de leite $\left(\mathrm{kg} \mathrm{dia}{ }^{-1}\right)$ e a produção de leite corrigida para $35 \mathrm{~g} \mathrm{~kg}^{-1}$ de gordura apresentaram comportamentos quadráticos $(\mathrm{P} \leq 0,05)$, com pontos máximos e mínimos, estimados, respectivamente, em $12,16 \mathrm{~g} \mathrm{~kg}^{-1} \mathrm{e}$ $154,5 \mathrm{~g} \mathrm{~kg}^{-1}$ de inclusão da torta (Tab. 3). 
Tabela 3. Médias da produção de leite (PL), produção de leite corrigida (PLC $35 \mathrm{~g} \mathrm{~kg}^{-1} \mathrm{GORD}$ ), eficiência da conversão alimentar da produção de leite corrigida (ECAPLC), teores de gordura (GORD), proteína bruta (PB), lactose (LAC), sólidos totais (ST) e extrato seco desengordurado (ESD) do leite produzido por vacas Holandesas alimentadas com diferentes quantidades de torta de macaúba

\begin{tabular}{|c|c|c|c|c|c|c|c|}
\hline \multirow{2}{*}{ Variáveis } & \multicolumn{4}{|c|}{ Inclusão de TM ( $\mathrm{g} \mathrm{kg}^{-1}$ da MS) } & \multirow{2}{*}{ E.P.M $\mathbf{M}^{1}$} & \multicolumn{2}{|c|}{ Efeito } \\
\hline & 0 & 100 & 200 & 300 & & $\mathrm{~L}$ & Q \\
\hline PL $\left(\mathrm{kg} \mathrm{dia}^{-1}\right)^{2}$ & 23,22 & 23,92 & 19,95 & 18,44 & 0,25 & 0,01 & 0,01 \\
\hline PLC $35 \mathrm{~g} \mathrm{~kg}^{-1}$ GORD $\left(\mathrm{kg} \mathrm{dia}^{-1}\right)^{3}$ & 26,00 & 21,32 & 20,65 & 22,84 & 0,37 & 0,01 & 0,01 \\
\hline ECAPLC $\left(\mathrm{kg} \mathrm{PLkgCMS}^{-1}\right)^{4}$ & 1,50 & 1,18 & 1,25 & 1,54 & 0,03 & 0,31 & 0,01 \\
\hline GORD $\left(\mathrm{g} \mathrm{kg}^{-1}\right)$ & 38,20 & 35,90 & 37,50 & 34,80 & 0,07 & 0,18 & 0,88 \\
\hline $\mathrm{PB}\left(\mathrm{g} \mathrm{kg}^{-1}\right)^{5}$ & 29,20 & 28,70 & 28,40 & 27,50 & 0,02 & 0,01 & 0,58 \\
\hline $\operatorname{LAC}\left(\mathrm{g} \mathrm{kg}^{-1}\right)^{6}$ & 44,50 & 46,00 & 45,20 & 44,30 & 0,01 & 0,36 & 0,01 \\
\hline $\mathrm{ST}\left(\mathrm{g} \mathrm{kg}^{-1}\right)^{7}$ & 122,10 & 120,30 & 119,90 & 115,70 & 0,07 & 0,01 & 0,39 \\
\hline $\operatorname{ESD}\left(\mathrm{g} \mathrm{kg}^{-1}\right)^{8}$ & 83,80 & 84,20 & 82,40 & 81,03 & 0,03 & 0,01 & 0,07 \\
\hline
\end{tabular}

"Erro padrão da média; ${ }^{2} \mathrm{y}=-0,00006 \mathrm{x}^{2}-0,00146 \mathrm{x}+23,57805\left(\mathrm{R}^{2}=0,73\right) ;{ }^{3} \mathrm{y}=0,0002 \mathrm{x}^{2}-0,0618 \mathrm{x}+25,952\left(\mathrm{R}^{2}=\right.$ $0,65) ;{ }^{4} \mathrm{y}=0,00002 \mathrm{x}^{2}-0,00432 \mathrm{x}+1,49093\left(\mathrm{R}^{2}=0,54\right) ;{ }^{5} \mathrm{y}=-0,0056 \mathrm{x}+29,353\left(\mathrm{R}^{2}=0,27\right) ;{ }^{6} \mathrm{y}=-0,0001 \mathrm{x}^{2}+$ $0,0172 \mathrm{x}+44,5944\left(\mathrm{R}^{2}=0,34\right) ;{ }^{7} \mathrm{y}=-0,0169 \mathrm{x}+121,46\left(\mathrm{R}^{2}=0,25\right) ;{ }^{8} \mathrm{y}=-0,0102 \mathrm{x}+84,413\left(\mathrm{R}^{2}=0,25\right)$.

Os resultados de produção podem ser reflexo direto do comportamento observado para o consumo de MS. Segundo Noller et al. (1997), a ingestão de MS é um dos fatores determinantes do desempenho dos animais, sendo o ponto inicial para o ingresso de nutrientes, principalmente de energia e proteína, necessários para o atendimento das exigências nutricionais de mantença e produção.

A eficiência da conversão alimentar da produção de leite também foi influenciada pela inclusão da torta $(\mathrm{P} \leq 0,05)$, reflexo direto dos comportamentos quadráticos observados para a produção de leite corrigida e para o consumo de MS (Tab. 2 e 3).

Os teores de gordura não diferiram $(\mathrm{P}>0,05)$ entre as dietas, apresentando média de $36,6 \mathrm{~g} \mathrm{~kg}^{-}$

1 (Tab. 3). Esperava-se aumento dos teores de gordura no leite com a inclusão do coproduto devido ao aumento dos teores de FDN de acordo com a sua inclusão (Tab. 1). Entretanto, o aumento dos teores do EE nas dietas (Tab. 1) pode ter reduzido a fermentação dessa fibra, por inibição do crescimento microbiano (Vargas et al., 2002), contrabalanceando a produção percentual de gordura.

Observa-se que o perfil de ácidos graxos da TM (Tab. 1) apresenta elevadas concentrações de ácidos graxos insaturados, com predominância do ácido oleico (C18:1), o que também pode ter contribuído para a não elevação dos teores de gordura produzida. Gaynor et al. (1994) demonstraram que a infusão abomasal de ácidos graxos oleicos-trans reduz a porcentagem de gordura do leite, devido à diminuição na síntese de outros ácidos graxos e reduzida atividade da enzima acyltransferase no tecido mamário, reduzindo assim a síntese de triglicerídeos.

Oliveira et al. (2007) observaram que o aumento no teor de lipídeos nas dietas reduziu a porcentagem de gordura do leite de vacas. Maiores teores de lipídeo insaturados podem afetar a bio-hidrogenação ruminal dos ácidos graxos, levando à síntese de ácidos graxos Trans, que são potentes inibidores da síntese de gordura na glândula mamária (Bauman e Griinari, 2003).

Os teores de proteína, sólidos totais e extrato seco desengordurado foram influenciados pela inclusão da TM, sendo observadas reduções lineares $(\mathrm{P} \leq 0,05)$. Já os teores de lactose apresentaram comportamento quadrático $(\mathrm{P} \leq 0,05)$, com ponto máximo estimado em $86 \mathrm{~g}$ $\mathrm{kg}^{-1}$ de inclusão de coproduto nas dietas.

Dentre os principais fatores que afetam a síntese de proteína do leite, estão a disponibilidade e o perfil de aminoácidos que chegam à glândula mamaria (Schwab et al., 1998 National..., 2001). 
Segundo Wu e Huber (1994), quando carboidratos fermentáveis, como o do milho, são substituídos por lipídeos, a produção de proteína microbiana tende a ser menor, assim como o pool de aminoácidos no animal, por causa do maior uso de aminoácidos para gluconeogênese. Como consequência, ocorre menor aporte de aminoácidos na glândula mamária, levando à menor produção de proteína no leite. Dessa forma, o alto teor de extrato etéreo das dietas com TM pode ter afetado negativamente o fluxo de proteína microbiana para o duodeno, fazendo com que houvesse baixo aporte de proteína metabolizável para síntese de proteína pela glândula mamária.

O comportamento quadrático de consumo de proteína, com redução de consumo a partir de $54,19 \mathrm{~g} \mathrm{~kg}^{-1}$ de coproduto nas dietas, pode ter reduzido o crescimento microbiano, reduzindo o suprimento de proteína metabolizável no intestino delgado. Parte dos aminoácidos absorvidos no intestino delgado, provenientes da digestão da proteína, é precursora de glicose no fígado (Silva et al., 2009), o que pode ter levado à redução da produção de lactose na glândula mamária e, consequentemente, ao de lactose no leite, a qual também apresentou comportamento quadrático.

Os animais alimentados com dietas contendo TM produziram menos sólidos totais no leite $(\mathrm{P} \leq 0,05)$, provavelmente em função da redução na produção de lactose e de proteína bruta. Segundo Bachman (1992), para que a proporção dos sólidos totais seja mantida, é necessário que todos os precursores de gordura e proteína estejam em proporções otimizadas e balanceadas; se isso não ocorrer, é provável que o teor de sólidos totais não se mantenha.

\section{CONCLUSÕES}

A inclusão da torta de macaúba em substituição ao milho em até $300 \mathrm{~g} \mathrm{~kg}^{-1}$ na matéria seca de dietas para vacas em lactação com produção de até $25 \mathrm{~kg} \mathrm{dia}^{-1}$ reduziu o consumo de matéria seca, a produção e os sólidos totais do leite.

\section{REFERÊNCIAS}

ALLEN, M.S. Effects of diet on short-term regulation of feed intake by lactating dairy cows. J. Dairy Sci., v.83, p.1598-1624, 2000.

AZEVEDO, R.A.; BICALHO, F.L.; ARAUJO, L. et al. Análise técnico-econômica de diferentes níveis da torta da torta de macaúba em dietas para vacas leiteiras. Arch. Zootec., v.62, p.1-4, 2013.

AZEVEDO, R.A.; RUFINO, L.M.A.; SANTOS A.C.R. et al. Desempenho de cordeiros alimentados com inclusão de torta de macaúba na dieta. Pesq. Agropec. Bras., v.47, p.16631668, 2012.

BACHMAN, K.C. Managing milk composition. In: van HORN, H.H.; WILCOX, C.J. (Eds.). Large dairy herd management. Champaign: American Dairy Science Association, 1992. p.110-121.

BAUMAN, D.E.; GRIINARI, J.M. Regulation and nutritional manipulation of milk fat: low-fat milk syndrome. Livest. Prod. Sci., v.70, p.15-29, 2001.

FORBES, J.M. Integration of regulatory signals controlling forage intake in ruminants. J. Anim. Sci., v.74, p.3029-3035, 1996.

GAYNOR, P.J.; ERDMAN, R.A.; TETER, B.B. et al. Milk fat yield and composition during abomasal infusion of cis or trans octadecenoates in Holstein cows. J. Dairy Sci., v.77, p.157-165, 1994.

HOLDEN, L.A. Comparison of methods of in vitro matter digestibility for ten feeds. J. Dairy Sci., v.82, p.1791-1794, 1999.

MACHMU ÈLLER, A.; KREUZER, M. Methane suppression by coconut oil and associated effects on nutrient and energy balance in sheep. Can. J. Anim. Sci., v.79, p.65-72, 1999.

MERTENS, D.R. Predicting intake and digestibility using mathematical models of ruminal function. J. Anim. Sci., v.64, p.15481558, 1987.

NATIONAL research council - NRC. Nutrient requeriments of dairy cattle. Washinton, D.C, 2001. 381p. 
NOLLER, C.H.; NASCIMENTO JR., D.; QUEIROZ, D.S. Determinando as exigências nutricionais de animais em pastejo. In: SIMPÓSIO SOBRE MANEJO DE PASTAGENS, 13., 1996, Piracicaba. Anais... Piracicaba, SP: FEALQ, 1997. p.319-351.

OLIVEIRA, A.S.; CAMPOS, J.M.S.; VALADARES FILHO, S.C. et al. Substituição do milho pela casca de café ou de soja em dietas para vacas leiteiras: comportamento ingestivo, concentração de nitrogênio ureico no plasma e no leite, balanço de compostos nitrogenados e produção de proteína microbiana. Rev. Bras. Zootec., v.36, p.205-215, 2007.

PEREIRA, E.S.; ARRUDA, A.M.V.; MIZUBUTI, I.Y., et al. Comportamento ingestivo de vacas em lactação alimentadas com diferentes fontes de volumosos conservados. Semina: Cienc. Agrárias, v.25, p.159-166, 2004.

PIMENTEL, P.G.; REIS, R.B.; LEITE, L.A. et al. Parâmetros da fermentação ruminal e concentração de derivados de purina de vacas em lactação alimentadas com castanha de caju. Arq. Bras. Med. Vet. Zootec., v.64, p.959-966, 2012.

PIRES, A.J.V.; VIEIRA, V.F.; SILVA, F.F. et al. Níveis de farelo de cacau (Theobroma cacao) na alimentação de bovinos. Rev. Electrón. Vet., v.6, p.1-10, 2005.

RUFINO, L.M.A.; BARRETO, S.M.P.; DUARTE, E.R. et al. Efeitos da inclusão de torta de macaúba sobre a população de protozoários ruminais de caprinos. Rev. Bras. Zootec., v.40, p.899-903, 2011.

SCHWAB, C.G. Methionine analogs for dairy cows: A subject revisited. California Animal Nutr. In: Conf., Fresno, CA. 1998.

SILVA, C.V.S.; LANA, R.P.; CAMPOS, J.M.S. Consumo, digestibilidade aparente dos nutrientes e desempenho de vacas leiteiras em pastejo com dietas com diversos níveis de concentrado e proteína bruta. Rev. Bras. Zootec., v.38, p.13721380, 2009.
SILVA, D.J.; QUEIROZ, A.C. Análise de alimentos (métodos químicos e biológicos). Viçosa: Imprensa Universitária, 2002. 3ed.

SILVA, H.G.O.; PIRES, A.J.V.; SILVA, F.F. et al. Farelo de cacau (Theobroma cocoa L.) e torta de dendê (Elaeis guineensis, Jacq) na alimentação de cabras em lactação: consumo e produção de leite. Rev. Bras. Zootec., v.34, p.1790-1798, 2005.

SNIFFEN, C.J.; O'CONNOR, J.D.; VAN SOEST, P.J.et al. A net carbohydrate and protein system for evaluating cattle diets. II Carbohydrate and protein availability. J. Anim. Sci., v.70, p.3562-3577, 1992.

STATISTICAL Analisys Sistem - SAS INSTITUTE. SAS user's guide. Version 9.0. Cary: SAS Institute, 2002.

TILLEY, J.M.A.; TERRY, R.A. A two-stage technique for the in vitro digestion of forage crops. J. Br. Grassl. Soc., v.18, p.104-111, 1963.

VAN SOEST, P.J. Nutritional ecology of the ruminant. Cornell University. 2.ed. 1994. 476p.

VARGAS, L.H.; LANA, R.P.; JHAM, G.N. et al. Adição de lipídios na ração de vacas leiteiras: parâmetros fermentativos ruminais, produção e composição do leite. Rev. Bras. Zootec., v.31, p.522-529, 2002.

WEISS, W.P. Energy prediction equations for ruminant feeds. In: CORNELL NUTRITION CONFERENCE FOR FEED MANUFACTURERS, 61., 1999, Proceedings... Ithaca: Cornell University, 1999. p.176-185.

WU, Z.; HUBER, J.T.; Relationship between dietary fat supplementation and milk protein concentration in lactating cows: a review. Livest. Prod. Sci. v.39, p.141-155, 1994. 